\title{
Design, Synthesis, and Antitumor Evaluation of 4-Amino- (1H)-pyrazole Derivatives as JAKs Inhibitors
}

\author{
Xuewu Liang, ${ }^{\dagger}$ Jie Zang, ${ }^{\dagger}$ Mengyuan Zhu, ${ }^{\ddagger}$ Qianwen Gao, ${ }^{\dagger}$ Binghe Wang, ${ }^{*}{ }^{\ddagger}$ Wenfang Xu, ${ }^{\dagger}$ \\ and Yingjie Zhang*, ${ }^{\dagger}$
}

${ }^{\dagger}$ Department of Medicinal Chemistry, School of Pharmacy, Shandong University, Ji'nan, Shandong 250012, P. R. China

${ }^{\ddagger}$ Department of Chemistry and Center for Diagnostics and Therapeutics, Georgia State University, Atlanta, Georgia 30303, United States

\section{Supporting Information}

ABSTRACT: Abnormalities in the JAK/STAT signaling pathway lead to many diseases such as immunodeficiency, inflammation, and cancer. Herein, we designed and synthesized a series of 4-amino(1H)-pyrazole derivatives as potent JAKs inhibitors for cancer treatment. Results from in vitro protein kinase inhibition experiments indicated that compounds $\mathbf{3 a}-\mathbf{f}$ and $\mathbf{1 1} \mathbf{b}$ are potent JAKs inhibitors. For example, the $\mathrm{IC}_{50}$ values of compound $3 \mathrm{f}$ against JAK1, JAK2, and JAK3 were 3.4, 2.2, and $3.5 \mathrm{nM}$, respectively. In cell culture experiments, compound $3 \mathbf{f}$ showed potent antiproliferative activity against various cell lines (PC-3, HEL, K562, MCF-7, and MOLT4) at low micromolar levels, while compound $\mathbf{1 1 b}$ showed selective cytotoxicity at submicromolar levels against $\mathrm{HEL}\left(\mathrm{IC}_{50}\right.$ : $0.35 \mu \mathrm{M})$ and $\mathrm{K} 562\left(\mathrm{IC}_{50}: 0.37 \mu \mathrm{M}\right)$ cell lines. It is worth noting that both $\mathbf{3 f}$ and $\mathbf{1 1 b}$ showed more potent antiproliferative activities than the approved JAKs inhibitor Ruxolitinib.

KEYWORDS: JAKs, Inhibitors, 4-Amino-(1H)-pyrazole, Anticancer

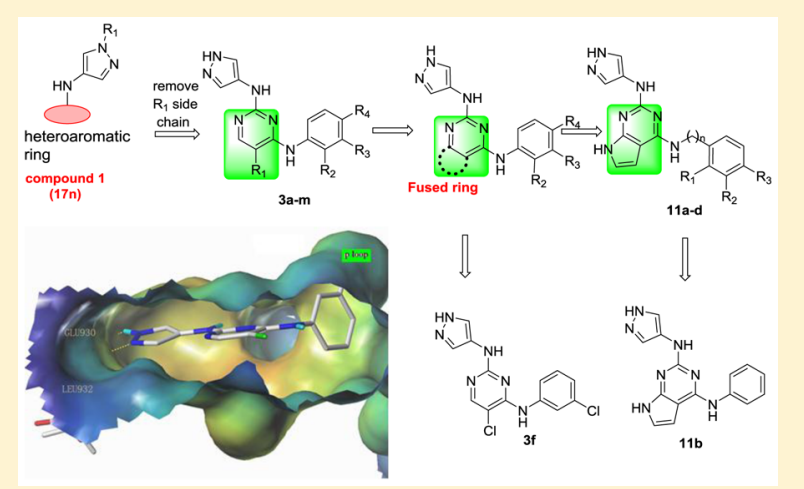

$\mathrm{T}$ he JAK/STAT signaling pathway plays critical roles in immunity, hematopoiesis, and cell growth. ${ }^{1}$ Abnormalities in the JAK/STAT signaling pathway lead to many diseases such as immunodeficiency, inflammation, and cancers. ${ }^{2}$ Constitutive activations of JAKs are correlated to oncogenesis. Dysregulation of JAK2 is discovered in patients with myeloproliferative neoplasms and childhood $\mathrm{T}$ cell acute lymphoblastic leukemia. ${ }^{3}$ Several hematologic malignancies including malignant lymphoma and myeloproliferative disorders are associated with mutations of JAK2. ${ }^{4}$ Some cytokines and growth factors bind to their receptors and then stimulate JAKs for the phosporylation of STAT3, which is a potential target for anticancer therapy. ${ }^{5}$ Persistent activation of the JAK/STAT3 signaling promotes proliferation and survival of tumor cells. ${ }^{6}$ Thus, the JAK/STAT signaling pathway is a promising antitumor target.

Inhibitors of JAKs are widely explored for treatment of immunodeficiency, inflammation, and cancer. Among the synthetic JAK inhibitors for the treatment of cancer identified to date (Figure 1), Ruxolitinib (Incyte's Jakafi) was approved by the US Food and Drug Administration (FDA) in 2013 for the treatment of myelofibrosis, a rare bone marrow cancer. Besides, it is in phase III clinical trials for the treatment of metastatic pancreatic cancer and phase II clinical trials for the treatment of multiple myeloma, leukemia, and colon cancer. ${ }^{7}$ There are several other JAKs inhibitors in clinical trials for cancer treatment (Figure 1). JAK2 inhibitor AZD1480 can inhibit STAT5

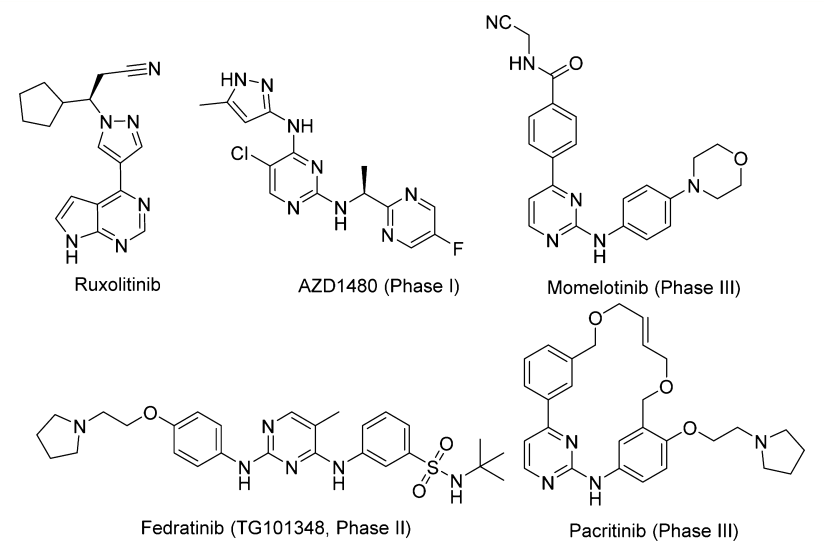

Figure 1. Approved or clinical JAK inhibitors for cancer treatment.

signaling in prostate cancer cells and then effectively inhibit castration-resistant growth of prostate cancer. ${ }^{8}$ JAK2 inhibitor TG101348 blocks JAK/STAT signaling leading to suppression of proliferation and induction of apoptosis and is used for the treatment of myelofibrosis. ${ }^{9}$ JAKs inhibitors Momelotinib and

Received: July 14, 2016

Accepted: August 23, 2016

Published: August 23, 2016 
Pacritinib are both developed for the treatment of myelofibrosis. $^{10}$

In our previous work, we discovered a series of 4-aminopyrazole derivatives as novel and potent JAK inhibitors (Figure 2). ${ }^{11}$ Structure-activity relationship (SAR) studies showed that

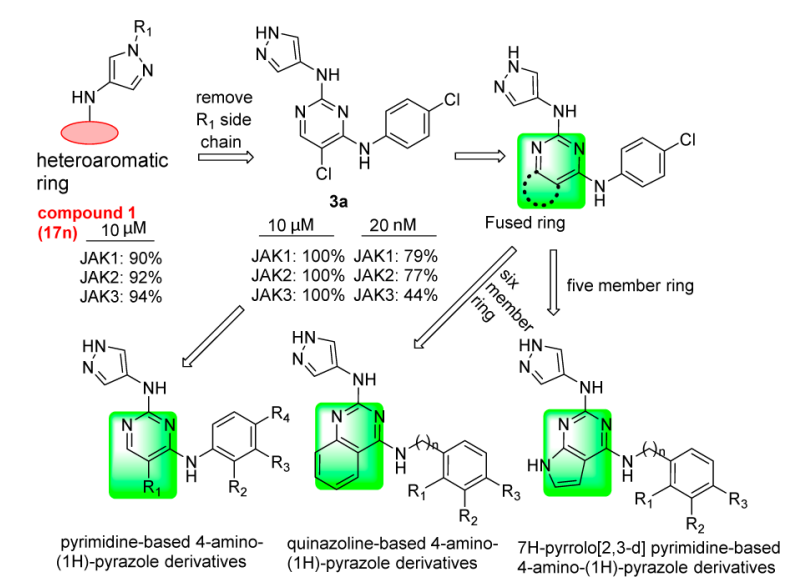

Figure 2. Design of 4-amino-( $1 H)$-pyrazole derivatives as JAKs inhibitor.

$\mathrm{R}_{1}$ group modifications in these analogues did not influence their JAK inhibition significantly. ${ }^{11}$ Such results indicate that the $\mathrm{R}_{1}$ side chain is not crucial to the interaction between these 4aminopyrazole derivatives and JAKs proteins. Herein, using $\mathbf{1}$ as a lead, a series of 4-amino- $(1 H)$-pyrazole derivatives were designed, synthesized, and evaluated as potent JAKs inhibitors. First, removing the $\mathrm{R}_{1}$ side chain of compound $\mathbf{1}$ led to compound 3a, which exhibited improved JAKs kinase inhibition at $10 \mu \mathrm{M}$. Then further structural modifications of $3 \mathrm{a}$ led to pyrimidine-based 4 -amino- $(1 H)$-pyrazole derivatives, quinazoline-based 4-amino- $(1 H)$-pyrazole derivatives, and $7 \mathrm{H}$-pyrrolo$[2,3-d]$ pyrimidine-based 4-amino- $(1 H)$-pyrazole derivatives (Figure 2).

Pyrimidine-based 4-amino-( $1 H)$-pyrazole derivatives $3 \mathbf{a}-\mathbf{m}$ were synthesized as described in Scheme 1. Generally, the reaction of 5-substituted-2,4-dichloropyrimidine with various aromatic amines under acidic $(\mathrm{HCl})$ or basic (DIPEA, $\mathrm{Et}_{3} \mathrm{~N}$, $\mathrm{Na}_{2} \mathrm{CO}_{3}$ ) conditions led to the intermediates $\mathbf{2 a}-\mathbf{m}$, which was

Scheme 1. Synthesis of Pyrimidine-Based 4-Amino-(1H)pyrazole Derivatives $3 a-m^{a}$

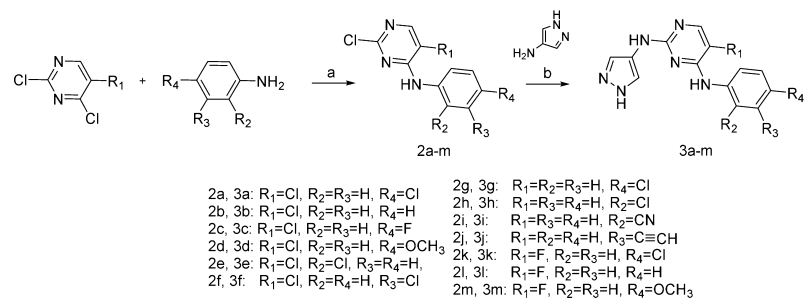

${ }^{a}$ Conditions and reagents: (a) For compounds $\mathbf{2 a}, \mathbf{2 b}$, and $2 \mathrm{~d}$, DIPEA, DMF, r.t., 16 h. For compound $2 \mathrm{c}, \mathrm{Na}_{2} \mathrm{CO}_{3}$, EtOH, r.t. overnight. For compound 2e, DIPEA, NMP, $100^{\circ} \mathrm{C}, 12 \mathrm{~h}$. For compounds $2 \mathrm{f}$ and $\mathbf{2 g}$, $\mathrm{Et}_{3} \mathrm{~N}, \mathrm{EtOH}, 50-80{ }^{\circ} \mathrm{C}$, overnight. For compound $\mathbf{2 h}, \mathrm{HCl}, \mathrm{H}_{2} \mathrm{O}$, r.t., 5 days. For compounds $2 \mathrm{i}$ and $2 \mathrm{l}, \mathrm{HCl}, \mathrm{H}_{2} \mathrm{O}, 50{ }^{\circ} \mathrm{C}, 5 \mathrm{~h}$. For compound $2 \mathrm{j}$, DIPEA, i-PrOH, $60{ }^{\circ} \mathrm{C}$, overnight. For compounds $2 \mathbf{k}$ and $2 \mathrm{~m}, \mathrm{H}_{2} \mathrm{O} / \mathrm{CH}_{3} \mathrm{OH}=3: 1,50{ }^{\circ} \mathrm{C}$, 5 h. (b) TFA, $n-\mathrm{BuOH}, 120^{\circ} \mathrm{C}$, $1 \mathrm{~h}$, microwave (MW irradiation). then reacted with $1 \mathrm{H}$-pyrazol-4-amine using TFA as a catalyst at high temperature to give target molecules $\mathbf{3 a}-\mathbf{m} .^{12}$

Quinazoline-based 4-amino-( $1 H)$-pyrazole derivatives $6 \mathbf{a}-\mathbf{f}$ were synthesized as shown in Scheme 2. The synthetic routes of

Scheme 2. Synthesis of Quinazoline-Based 4-Amino-(1H)pyrazole Derivatives $6 a-f^{a}$

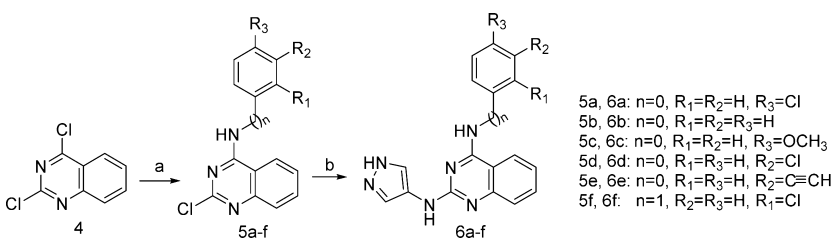

${ }^{a}$ Conditions and reagents: (a) $\mathrm{CH}_{3} \mathrm{COONa}, \mathrm{THF} / \mathrm{H}_{2} \mathrm{O}=3: 1$, r.t. to $60{ }^{\circ} \mathrm{C}$, overnight. (b) $n$-BuOH, $120{ }^{\circ} \mathrm{C}, 1 \mathrm{~h}$, microwave (MW irradiation).

derivatives $6 \mathbf{a}-\mathbf{f}$ were similar to that of Scheme 1 . Intermediates $\mathbf{5 a}-\mathbf{f}$ were obtained from reaction of 2,4-dichloroquinazoline with various amines under basic condition of $\mathrm{CH}_{3} \mathrm{COONa}{ }^{13}$ Then, $\mathbf{5 a}-\mathbf{f}$ reacted with $1 \mathrm{H}$-pyrazol-4-amine at high temperature to give target molecules $\mathbf{6 a}-\mathbf{f}$.

$7 \mathrm{H}$-Pyrrolo[2,3-d] pyrimidine-based 4-amino- $(1 H)$-pyrazole derivatives 11a-d were synthesized as shown in Scheme 3. The

Scheme 3. Synthesis of $7 H$-Pyrrolo $[2,3-d]$ pyrimidine-Based 4-Amino-(1H)-pyrazole Derivatives $11 \mathrm{a}-\mathrm{d}^{a}$

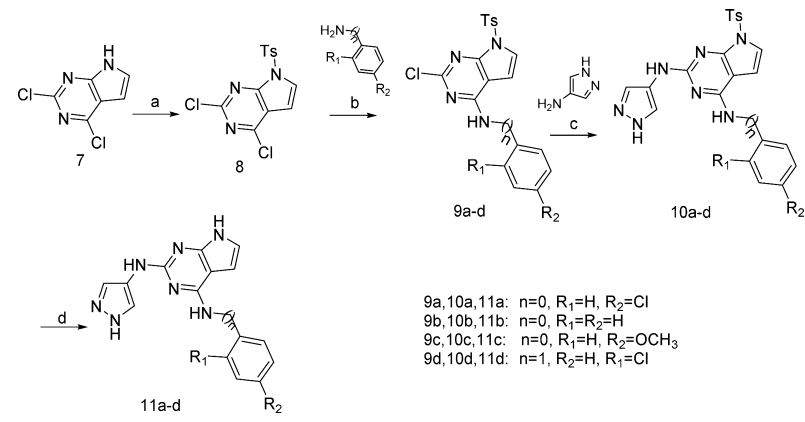

${ }^{a}$ Conditions and reagents: (a), TsCl, $\mathrm{Et}_{3} \mathrm{~N}, \mathrm{DMAP}, \mathrm{CH}_{2} \mathrm{Cl}_{2}$. r.t., 5 h. (b) DIPEA, $n$-BuOH, $100{ }^{\circ} \mathrm{C}$, overnight. (c) TFA, $n$ - $\mathrm{BuOH}, 120^{\circ} \mathrm{C}, 1$ h, microwave (MW irradiation). (d) $\mathrm{Cs}_{2} \mathrm{CO}_{3}, \mathrm{H}_{2} \mathrm{O} / \mathrm{CH}_{3} \mathrm{OH} /$ dioxane $=1: 3: 3(\mathrm{v} / \mathrm{v} / \mathrm{v}), 80{ }^{\circ} \mathrm{C}, 6 \mathrm{~h}$.

starting material 2,4-dichloro-7H-pyrrolo[2,3-d] pyrimidine was protected by 4 -methylbenzenesulfonyl chloride ${ }^{14}$ to give compound 8, which was reacted with various amines, leading to intermediates $\mathbf{9 a}-\mathbf{d}$, under basic conditions at high temperature. Intermediates $\mathbf{9 a}-\mathbf{d}$ reacted with $1 \mathrm{H}$-pyrazol-4-amine using TFA as a catalyst at high temperature to produce intermediates $10 \mathbf{a}-\mathbf{d}$. Ts-deprotection of $10 \mathbf{a}-\mathbf{d}$ yielded target molecules $11 \mathbf{a}-\mathbf{d} .^{15}$

The 4-amino- $(1 H)$-pyrazole derivatives were screened for their in vitro kinase inhibitory activities toward JAK1, JAK2, and JAK 3 at 10,1 , and $0.1 \mu \mathrm{M}$ and 40 and $20 \mathrm{nM}$. Because we are only interested in compounds with nanomolar inhibition activities, the final screening was done at $20 \mathrm{nM}$. Staurosporine (a prototypical ATP-competitive kinase inhibitor; $\mathrm{IC}_{50}$ : JAK1 $3 \mathrm{nM}$, JAK2 $2 \mathrm{nM}$, JAK3 $1 \mathrm{nM}$ ) and Ruxolitinib (an approved JAK inhibitor; inhibition at $20 \mathrm{nM}$ : JAK1 97\%, JAK2 99\%, JAK3 95\%) were used as positive controls. ${ }^{16}$ All the inhibition results were shown in Figures 3-6. 


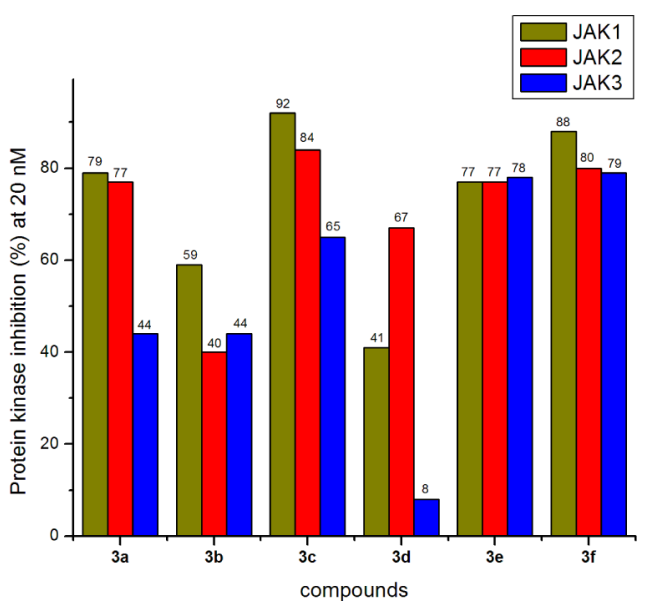

Figure 3. In vitro inhibitory activity against JAK1, JAK2, and JAK3.

Results in Figure 3 showed that compounds $\mathbf{3 a}-\mathbf{3 f}$ exhibited remarkable inhibitory activities against JAK1, JAK2, and JAK3 at $20 \mathrm{nM}$ with the exception of compound $3 \mathrm{~d}$, which was not active against JAK3 at $20 \mathrm{nM}$. For example, at $20 \mathrm{nM}$, compound $3 \mathrm{f}$ inhibited protein kinase activities of $88 \%, 80 \%$, and $79 \%$ against JAK1, JAK2, and JAK3 respectively. Further evaluation revealed that the $\mathrm{IC}_{50}$ values of $\mathbf{3 f}$ against JAK1, JAK2, and JAK3 were 3.4, 2.2 , and $3.5 \mathrm{nM}$, respectively. Generally, different substituents on the phenyl ring were well tolerated.

Results in Figure 4 showed that replacing the $\mathrm{Cl}$ group on pyrimidine ring with other groups, such as $\mathrm{H}$ or $\mathrm{F}$ could lead to

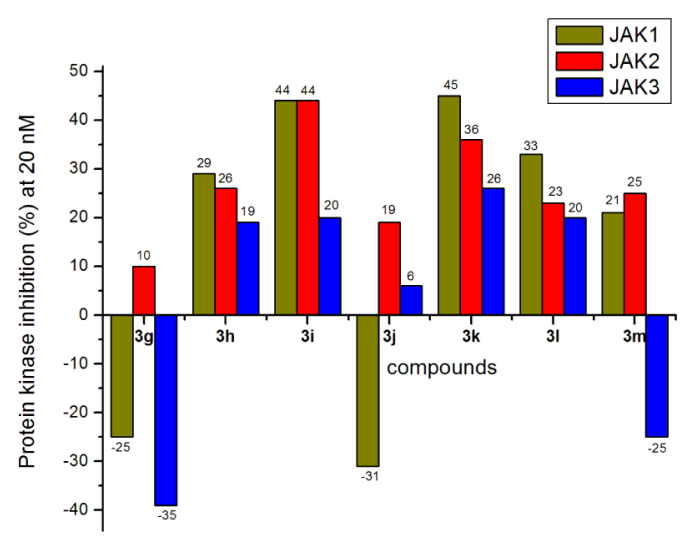

Figure 4. In vitro inhibitory activity against JAK1, JAK2, and JAK3.

reduced JAKs inhibition. For example, compounds $\mathbf{3 g}$ and $\mathbf{3 k}$ were much less potent than 3a (Figure 3 ). Taking the results in Figure 3 and Figure 4 together, we conclude that $R_{1}$ group on pyrimidine ring contributed much more to JAKs inhibition than $\mathrm{R}_{2}, \mathrm{R}_{3}$, and $\mathrm{R}_{4}$ groups on the phenyl ring.

From the data shown in Figure 5, we could see that quinazoline-based 4-amino-( $1 H$ )-pyrazole derivatives $\mathbf{6 a - f}$ almost completely lost their inhibitory activities toward JAKs at 20 $\mathrm{nM}$. This indicated that a large fused ring, such as quinazoline, was not beneficial to binding with JAKs.

Comparing the compounds in Figure 6 with compounds in Figure 3, we could see that $7 \mathrm{H}$-pyrrolo $[2,3-d]$ pyrimidine-based 4-amino-( $1 H$ )-pyrazole derivatives (Figure 6) showed moderate JAKs inhibition at $20 \mathrm{nM}$, but less potent than pyrimidine-based 4-amino-( $1 H)$-pyrazole derivatives (Figure 3). For example,

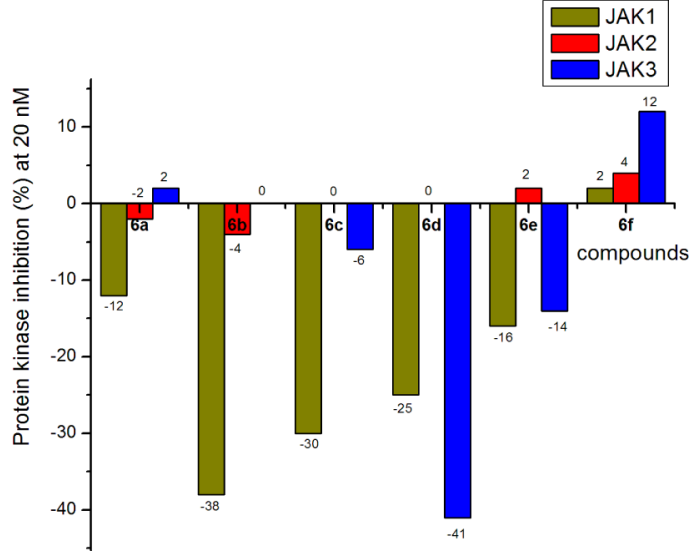

Figure 5. In vitro inhibitory activity against JAK1, JAK2, and JAK3.

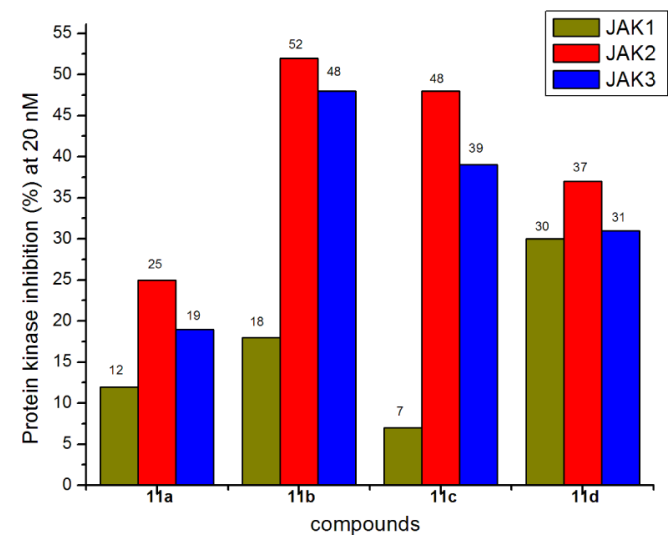

Figure 6. In vitro inhibitory activity against JAK1, JAK2, and JAK3.

compounds 11a, 11b, and 11c in Figure 6 were less potent than 3a, 3b, and 3d in Figure 3, respectively.

It was reported that mutation in the $\mathrm{JH} 2$ pseudokinase domain of the Janus kinase 2 gene (JAK2 V617F) existed in HEL (human erythroleukemia) cell line. ${ }^{17}$ Therefore, all target compounds were screened against HEL cell line at the concentration of $5 \mu \mathrm{M}$ to evaluate their in vitro anticancer activities. Results in Figure 7 showed that among these analogues, compounds $3 \mathbf{a}-\mathbf{f}$ and $11 \mathbf{a}-$ d exhibited superior antiproliferative activities against HEL cell line (indicated by the red column) than the other compounds we

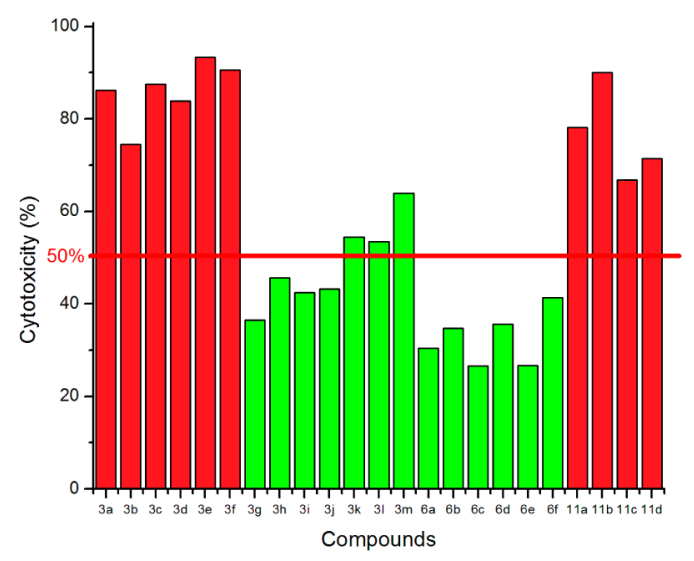

Figure 7. Activity screening against HEL cell line at the concentration of $5 \mu \mathrm{M}$. The plates containing compounds and cells were incubated for 48 $\mathrm{h}$ in MTT assay. 
Table 1. Inhibitory Activities of Compounds Against Tumor Cell Lines

\begin{tabular}{|c|c|c|c|c|c|}
\hline \multirow[b]{2}{*}{ compd } & \multicolumn{5}{|c|}{$\mathrm{IC}_{50}{ }^{a}(\mu \mathrm{M})$} \\
\hline & PC-3 & MCF-7 & HEL & K562 & MOLT4 \\
\hline $3 a$ & $2.57 \pm 0.22$ & $1.93 \pm 0.02$ & $1.53 \pm 0.15$ & $1.70 \pm 0.27$ & $1.37 \pm 0.23$ \\
\hline $3 b$ & $5.38 \pm 0.62$ & $3.66 \pm 1.29$ & $5.93 \pm 0.01$ & $>8.3^{b}$ & $>5$ \\
\hline $3 c$ & $1.03 \pm 0.25$ & $1.87 \pm 0.01$ & $1.18 \pm 0.15$ & $1.86 \pm 0.29$ & $3.28 \pm 0.45$ \\
\hline $3 d$ & $2.30 \pm 0.98$ & $\mathrm{ND}^{c}$ & $1.76 \pm 0.24$ & $2.08 \pm 0.33$ & ND \\
\hline $3 e$ & $1.13 \pm 0.08$ & $1.10 \pm 0.01$ & $1.24 \pm 0.19$ & $1.29 \pm 0.21$ & $1.26 \pm 0.15$ \\
\hline $3 f$ & $1.08 \pm 0.05$ & $1.33 \pm 0.42$ & $1.08 \pm 0.06$ & $0.77 \pm 0.05$ & $1.61 \pm 0.35$ \\
\hline $3 \mathbf{k}$ & $10.38 \pm 0.97$ & ND & $3.96 \pm 1.05$ & $3.79 \pm 0.86$ & $\mathrm{ND}$ \\
\hline $11 b$ & $4.47 \pm 1.29$ & $>5$ & $0.35 \pm 0.07$ & $0.37 \pm 0.11$ & $>5$ \\
\hline $11 d$ & $13.52 \pm 1.98$ & $>5$ & $\mathrm{ND}$ & $3.72 \pm 0.71$ & $>5$ \\
\hline $6 d$ & ND & $>5$ & $9.71 \pm 0.99$ & $>8.3$ & ND \\
\hline Ruxolitinib & $>5$ & $>5$ & $2.62 \pm 0.19$ & $10.3 \pm 0.3$ & $15.8 \pm 1.4$ \\
\hline
\end{tabular}

${ }^{a} \mathrm{IC}_{50}$ are mean of two or three experiments, and standard deviation is given. ${ }^{b} \mathrm{IC}_{50}$ value of this compound is larger than 8.3 or $5 .{ }^{c} \mathrm{ND}$, not determined.

synthesized. These data were generally consistent with their JAKs inhibitory potency.

Considering their potent JAKs inhibitory activities and antiproliferative potency against the HEL cell line, ten compounds (3a-f, $3 \mathbf{k}, 11 \mathbf{b}, 1 \mathbf{1 d}$, and $\mathbf{6 d}$ ) were chosen for further antiproliferative evaluation against human prostate cancer PC-3, human breast cancer MCF-7, human erythroleukemia HEL, human myelogenous leukemia K562, and human lymphoid leukemia MOLT4 cell lines. Ruxolitinib was used as a positive control. The results in Table 1 showed that most of the ten compounds possessed potent anticancer activity in vitro. Among these compounds, $\mathbf{3 a}, \mathbf{3 c}, \mathbf{3 e}$, and $\mathbf{3 f}$ were cytotoxic to all five tested cell lines, while $\mathbf{1 1} \mathbf{b}$ exhibited remarkably selective cytotoxicity to HEL ( $\left.\mathrm{IC}_{50}: 0.35 \mu \mathrm{M}\right)$ and $\mathrm{K} 562\left(\mathrm{IC}_{50}: 0.37 \mu \mathrm{M}\right)$. It is worth emphasizing that, though less potent than Ruxolitinib in JAK inhibition, most of our compounds exhibited more potent cytotoxicity than Ruxolitinib (Table 1), indicating that our compounds might have off-target effects. Therefore, representative compounds $3 \mathbf{f}$ and $\mathbf{1 1 b}$ were evaluated against 14 other cancer related kinases. The results in Figure 8 showed that at 20

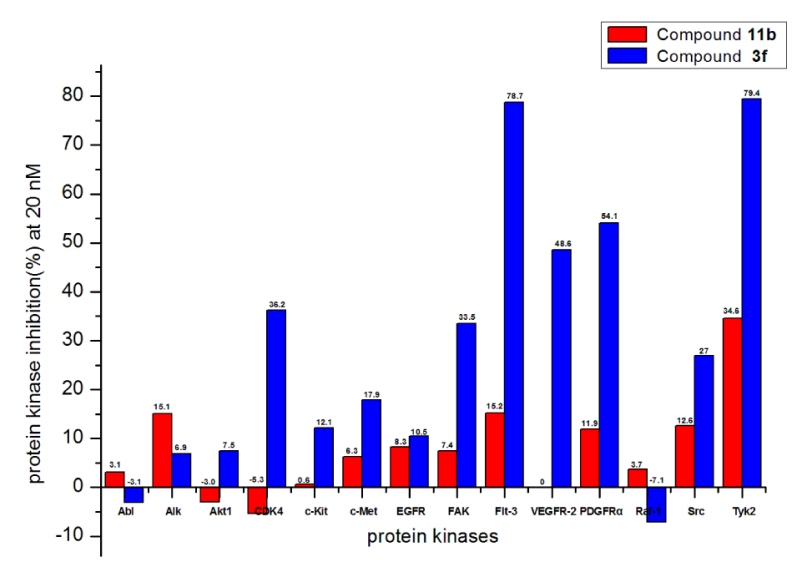

Figure 8. Selectivity profile of compounds $3 \mathrm{f}$ and $\mathbf{1 1 b}$ on 14 protein kinases at $20 \mathrm{nM}$.

$\mathrm{nM}$ compound $3 \mathrm{f}$ was active against a number of kinases including Flt-3, VEGFR-2, PDGFR $\alpha$, and TYK2, while compound $11 \mathrm{~b}$ exhibited very good selectivity against JAK2 and JAK 3 over the other tested kinases. These results could explain why $\mathbf{3 f}$ were cytotoxic to all five cell lines, while $\mathbf{1 1} \mathbf{b}$ was more selective against JAK/STAT pathway promoted cell lines, such as $\mathrm{HEL}^{18,19}$ and $\mathrm{K} 562 .^{20-22}$ However, our kinase panel screening results still could not explain why $11 \mathbf{b}$ were more cytotoxic than Ruxolitinib. Further anticancer mechanism research of $11 \mathbf{b}$ is warranted.

To investigate the binding mode of these 4-amino- $(1 H)$ pyrazole derivatives in JAK2, the most potent compound $\mathbf{3 f}$ was docked into the ATP binding pocket of JAK2 using SYBYL-X 2.0 (Figure 9). The results shown in Figure 9 suggested that the

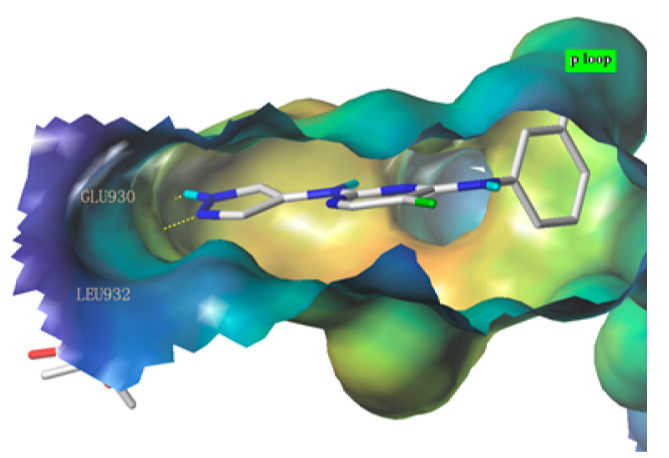

Figure 9. Docking of compound $3 \mathrm{f}$ with JAK2 (PDB code 3FUP).

$-\mathrm{NH}$ and $=\mathrm{N}$ moieties of pyrazole in compound $3 \mathrm{f}$ could form hydrogen bonds with GLU930 and LEU932. These hydrogen interactions were the crucial part for the protein kinase inhibition. The $-\mathrm{NH}$ moiety of pyrazole as hydrogen donor was necessary for the improvement of binding to JAKs. This maybe the reason why the kinase inhibitory activities of 4-amino$(1 \mathrm{H})$-pyrazole derivatives were much more potent than their parent 4-amino-pyrazole derivatives. For example, compound 3a reported here is much more potent than its parent $17 \mathbf{n}$ (compound 1) reported in our previous research. ${ }^{11}$ Additional docking with the compound that has a fused phenyl ring (compound 6d) was also studied. Docking results showed compounds $3 \mathrm{f}$ and $\mathbf{6 d}$ share a similar binding mode. To understand why compound $\mathbf{6 d}$ showed weak activity, a molecular dynamics (MD) simulation and a molecular mechanics PoissonBoltzmann surface area (MM/PBSA) energy decomposition calculation experiment were conducted. Our result showed that the fused phenyl ring and the side chain of ASP939 gave a 1.50 $\mathrm{kcal} / \mathrm{mol}$ negative energy contribution in binding (Figure 10). Besides, MD simulation indicated that the fused ring position is solvent accessible: it is exposed to water (Figure 11). These two 


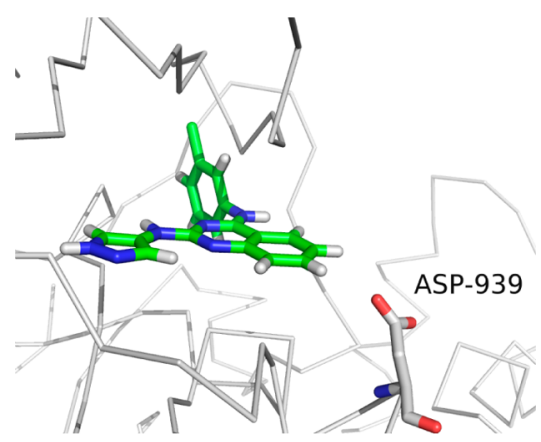

Figure 10. Docking of compound 6d with JAK2 (PDB code 3FUP).

reasons may explain why adding an additional large hydrophobic ring, such as a fused phenyl ring, does not favor binding.

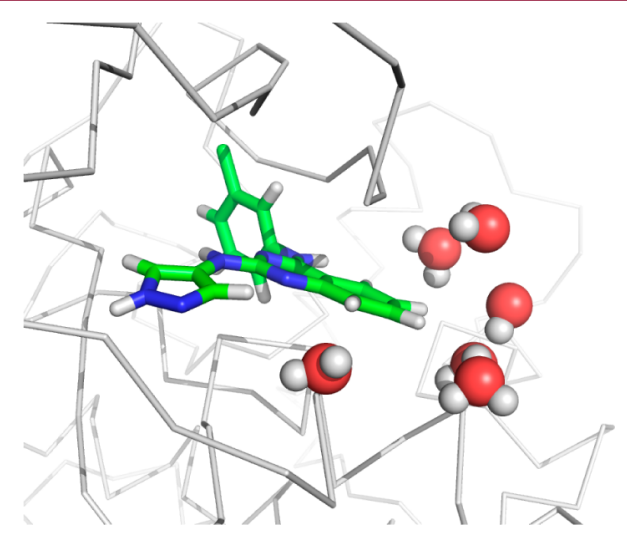

Figure 11. Fused phenyl ring is exposed to water in MD simulation. Water molecules within $4 \AA$ of compound 6d were selected for visualization (spheres).

In summary, a series of 4-amino-( $1 H)$-pyrazole derivatives as potent JAKs inhibitors were designed, synthesized, and evaluated. In enzyme inhibition screenings, many of the compounds reached $\mathrm{IC}_{50}$ values below $20 \mathrm{nM}$. In cell-based assays, compound $\mathbf{3 f}$ showed potent cytotoxicity against a wide variety of cell lines at micromolar levels. Compound $\mathbf{1 1 b}$ possessed very potent cytotoxicity against HEL and K562 cell lines with $\mathrm{IC}_{50}$ values in the submicromolar range, which were over 10-fold lower than in PC-3, MCF-7, and MOLT4 cell lines. Further kinase panel screening results revealed that compound $3 \mathbf{f}$ is a pan-kinase inhibitor, while $\mathbf{1 1 b}$ is a highly selective JAK2 and JAK3 inhibitor, which could be used as lead compound for further structural optimizations to find more potent and selective JAKs inhibitors. Moreover, considering the discrepancy between JAKs inhibition and cytotoxicity when compared with Ruxolitinib, more detailed mechanistic studies are warranted for $\mathbf{1 1 b}$

\section{ASSOCIATED CONTENT}

\section{S Supporting Information}

The Supporting Information is available free of charge on the ACS Publications website at DOI: 10.1021/acsmedchemlett.6b00247.

Experimental section and characterization data (HRMS, ${ }^{1} \mathrm{H}$ NMR) for new compounds (PDF)

\section{AUTHOR INFORMATION}

\section{Corresponding Authors}

*E-mail: wang@gsu.edu.

*E-mail: zhangyingjie@sdu.edu.cn.

\section{Funding}

This work was supported by the National High-Tech R\&D Program of China (863 Program) (Grant No. 2014AA020523), National Natural Science Foundation of China (Grant Nos. 21302111, 81373282, 21172134), Young Scholars Program of Shandong University (YSPSDU, Grant NO. 2016WLJH33), and Major Project of Science and Technology of Shandong Province (2015ZDJS04001).

\section{Notes}

The authors declare no competing financial interest.

\section{ACKNOWLEDGMENTS}

This work used the Extreme Science and Engineering Discovery Environment (XSEDE), which is supported by National Science Foundation grant number ACI-1053575. We also gratefully acknowledge the use of Orion that is supported by Georgia State University's Research Solutions.

\section{ABBREVIATIONS}

JAK, Janus kinase; STAT, signal transducers and activators of transcription; DIPEA, N,N-diisopropylethylamine; DMAP, 4dimethylaminopyridine; TFA, trifluoroacetic acid; DMF, dimethylformamide; NMP, N-methyl-2-pyrrolidone

\section{REFERENCES}

(1) Clark, J. D.; Flanagan, M. E.; Telliez, J. B. Discovery and development of Janus kinase (JAK) inhibitors for inflammatory diseases. J. Med. Chem. 2014, 57, 5023-38.

(2) Minegishi, Y.; Karasuyama, H. Defects in Jak-STAT-mediated cytokine signals cause hyper-IgE syndrome: lessons from a primary immunodeficiency. Int. Immunol. 2009, 21, 105-12.

(3) Xiong, H.; Zhang, Z. G.; Tian, X. Q.; Sun, D. F.; Liang, Q. C.; Zhang, Y.J.; Lu, R.; Chen, Y. X.; Fang, J. Y. Inhibition of JAK1, 2/STAT3 signaling induces apoptosis, cell cycle arrest, and reduces tumor cell invasion in colorectal cancer cells. Neoplasia 2008, 10, 287-97.

(4) Dawson, M. A.; Curry, J. E.; Barber, K.; Beer, P. A.; Graham, B.; Lyons, J. F.; Richardson, C. J.; Scott, M. A.; Smyth, T.; Squires, M. S.; Thompson, N. T.; Green, A. R.; Wallis, N. G. AT9283, a potent inhibitor of the Aurora kinases and Jak2, has therapeutic potential in myeloproliferative disorders. Br. J. Haematol. 2010, 150, 46-57.

(5) Inghirami, G.; Chiarle, R.; Simmons, W. J.; Piva, R.; Schlessinger, K.; Levy, D. E. New and old functions of STAT3: a pivotal target for individualized treatment of cancer. Cell Cycle 2005, 4, 1131-3.

(6) Liu, L.; Nam, S.; Tian, Y.; Yang, F.; Wu, J.; Wang, Y.; Scuto, A.; Polychronopoulos, P.; Magiatis, P.; Skaltsounis, L.; Jove, R. 6Bromoindirubin- $3^{\prime}$-oxime inhibits JAK/STAT3 signaling and induces apoptosis of human melanoma cells. Cancer Res. 2011, 71, 3972-9.

(7) Bryan, J. C.; Verstovsek, S. Overcoming treatment challenges in myelofibrosis and polycythemia vera: the role of ruxolitinib. Cancer Chemother. Pharmacol. 2016, 77, 1125-42.

(8) Gu, L.; Liao, Z.; Hoang, D. T.; Dagvadorj, A.; Gupta, S.; Blackmon, S.; Ellsworth, E.; Talati, P.; Leiby, B.; Zinda, M.; Lallas, C. D.; Trabulsi, E. J.; McCue, P.; Gomella, L.; Huszar, D.; Nevalainen, M. T. Pharmacologic inhibition of Jak2-Stat5 signaling By Jak2 inhibitor AZD1480 potently suppresses growth of both primary and castrateresistant prostate cancer. Clin. Cancer Res. 2013, 19, 5658-74.

(9) Pardanani, A.; Gotlib, J. R.; Jamieson, C.; Cortes, J. E.; Talpaz, M.; Stone, R. M.; Silverman, M. H.; Gilliland, D. G.; Shorr, J.; Tefferi, A. Safety and efficacy of TG101348, a selective JAK2 inhibitor, in myelofibrosis. J. Clin. Oncol. 2011, 29, 789-96. 
(10) Hart, S.; Goh, K. C.; Novotny-Diermayr, V.; Hu, C. Y.; Hentze, H.; Tan, Y. C.; Madan, B.; Amalini, C.; Loh, Y. K.; Ong, L. C.; William, A. D.; Lee, A.; Poulsen, A.; Jayaraman, R.; Ong, K. H.; Ethirajulu, K.; Dymock, B. W.; Wood, J. W. SB1518, a novel macrocyclic pyrimidinebased JAK2 inhibitor for the treatment of myeloid and lymphoid malignancies. Leukemia 2011, 25, 1751-9.

(11) Liang, X. W.; Huang, Y. X.; Zang, J.; Gao, Q. W.; Xu, W. F.; Wang, B. H.; Zhang, Y. J. Design, synthesis and preliminary biological evaluation of 4-aminopyrazole derivatives as novel and potent JAKs inhibitors. Bioorg. Med. Chem. 2016, 24, 2660-72.

(12) Breslin, H. J.; Lane, B. M.; Ott, G. R.; Ghose, A. K.; Angeles, T. S.; Albom, M. S.; Cheng, M.; Wan, W.; Haltiwanger, R. C.; Wells-Knecht, K. J.; Dorsey, B. D. Design, synthesis, and anaplastic lymphoma kinase (ALK) inhibitory activity for a novel series of 2,4,8,22-tetraazatetracyclo [ 1 4.3.1.1(3), ( 7 ). 1 (9), ( 1 ) (3)] docos a 1(20),3(22),4,6,9(21),10,12,16,18-nonaene macrocycles. J. Med. Chem. 2012, 55, 449-64.

(13) Van Horn, K. S.; Burda, W. N.; Fleeman, R.; Shaw, L. N.; Manetsch, R. Antibacterial activity of a series of N2,N4-disubstituted quinazoline-2,4-diamines. J. Med. Chem. 2014, 57, 3075-93.

(14) Song, Y. H.; Xu, Q.; Bauer, S. M.; Jia, Z. Z. Preparation of pyrimidine, pyrrolopyrimidine and purine-based analogs as inhibitors of protein kinases. PCT Int. Appl. 2009, WO 2009131687A2.

(15) Su, Q.; Ioannidis, S.; Chuaqui, C.; Almeida, L.; Alimzhanov, M.; Bebernitz, G.; Bell, K.; Block, M.; Howard, T.; Huang, S.; Huszar, D.; Read, J. A.; Rivard Costa, C.; Shi, J.; Su, M.; Ye, M.; Zinda, M. Discovery of 1-methyl-1H-imidazole derivatives as potent Jak2 inhibitors. J. Med. Chem. 2014, 57, 144-58.

(16) Peng, H.; Liao, H. F. Staurosporine induces megakaryocytic differentiation through the upregulation of JAK/Stat3 signaling pathway. Ann. Hematol. 2011, 90, 1017-29.

(17) Weber, A.; Borghouts, C.; Brendel, C.; Moriggl, R.; Delis, N.; Brill, B.; Vafaizadeh, V.; Groner, B. Stat5 Exerts Distinct, Vital Functions in the Cytoplasm and Nucleus of Bcr-Abl ${ }^{+} \mathrm{K} 562$ and Jak2(V617F) ${ }^{+} \mathrm{HEL}$ Leukemia Cells. Cancers 2015, 7, 503-37.

(18) Quentmeier, H. JAK2 V617F tyrosine kinase mutation in cell lines derived from myeloproliferative disorders. Leukemia 2006, 20 (3), 471476.

(19) Walters, D. K. Phosphoproteomic analysis of AML cell lines identifies leukemic oncogenes. Leuk. Res. 2006, 30 (9), 1097-1104.

(20) Dalgıç, C. T. Investigating the Role of JAK/STAT Pathway on Dasatinib-Induced Apoptosis for CML Cell Model K562. Clinical Lymphoma, Myeloma \& Leukemia 2015, 15 (1), 161-6.

(21) de Groot, Rolf P. STAT5 Activation by BCR-Abl Contributes to Transformation of K562 Leukemia Cells. Blood 1999, 94 (3), 11081112.

(22) Kindler, T. In BCR-ABL-positive cells, STAT-5 tyrosinephosphorylation integrates signals induced by imatinib mesylate and Ara-C. Leukemia 2003, 17, 999-1009. 